\title{
Seafloor monitoring west of Helgoland (German Bight, North Sea) using the acoustic ground discrimination system RoxAnn
}

\author{
H. Christian Hass ${ }^{1}$ (D) - Finn Mielck ${ }^{1}$ - Dario Fiorentino ${ }^{1}$ - Svenja Papenmeier ${ }^{1}$ • \\ Peter Holler $^{2}$ - Alexander Bartholomä ${ }^{2}$
}

Received: 11 February 2016 / Accepted: 4 November 2016

(C) Springer-Verlag Berlin Heidelberg 2016

\begin{abstract}
Marine habitats of shelf seas are in constant dynamic change and therefore need regular assessment particularly in areas of special interest. In this study, the single-beam acoustic ground discrimination system RoxAnn served to assess seafloor hardness and roughness, and combine these parameters into one variable expressed as RGB (red green blue) color code followed by k-means fuzzy cluster analysis (FCA). The data were collected at a monitoring site west of the island of Helgoland (German Bight, SE North Sea) in the course of four surveys between September 2011 and November 2014. The study area has complex characteristics varying from outcropping bedrock to sandy and muddy sectors with mostly gradual transitions. RoxAnn data enabled to discriminate all seafloor types that were suggested by ground-truth information (seafloor samples, video). The area appears to be quite stable overall; sediment import (including fluid mud) was detected only from the NW. Although hard substrates (boulders, bedrock) are clearly identified, the signal can be modified by inclination and biocover. Manually, six RoxAnn zones were identified; for the FCA, only three classes are suggested. The latter classification based on 'hard' boundaries would suffice
\end{abstract}

Responsible guest editor: C. Winter

Electronic supplementary material The online version of this article (doi:10.1007/s00367-016-0483-1) contains supplementary material, which is available to authorized users.

H. Christian Hass

christian.hass@awi.de

1 Alfred Wegener Institute, Helmholtz Centre for Polar and Marine Research, Wadden Sea Research Station, Hafenstraße 43, 25992 List/ Sylt, Germany

2 Senckenberg am Meer, Department for Marine Research, Südstrand 40, 26382 Wilhelmshaven, Germany for stakeholder issues, but the former classification based on 'soft' boundaries is preferred to meet state-of-the-art scientific objectives.

\section{Introduction}

Producing detailed maps of the seafloor including both water depth and textural characteristics has always been a challenge to scientists and stakeholders. Such marine habitat maps are an essential tool to comprehend the complexity, spatial diversity, and ecological status of the seafloor (e.g., Kenny et al. 2003; Bartholomä 2006; ICES 2007; Cogan et al. 2009; Brown et al. 2011; Mielck et al. 2014; Henriques et al. 2015). In earlier times, the collection of samples, photographs and videos, combined with diver surveys followed by interpolation of point data over larger distances was the only feasible way to gain information on sedimentary features in terms of granulometry, bedforms and associated benthos (e.g., Figge 1981; cf. Dean et al. 2013). Today, ground truthing via samples and videos is still necessary, but acoustic swath systems like multi-beam echosounders (MBESs) and sidescan sonars are able to produce seamless area-wide maps of the backscatter characteristics and topography of the seafloor (Lurton and Lamarche 2015). Linking such reflectance patterns with ground-truthed information provides a strong data base for habitat-map production (Huang et al. 2012).

In contrast to MBES systems, single-beam echosounders (SBESs) are able to analyze the echo returns in a more sophisticated way, providing more elaborate information about the seafloor. They lack spatial coverage, however, which makes complex interpolation methods necessary (Foster-Smith et al. 2004; Henriques et al. 2015). In-depth analysis of echo characteristics such as statistical wave-form analysis or multipleecho integration methods are largely restricted to SBESs 
(Gavrilov et al. 2005). RoxAnn - the system chosen for this study - is one of the single-beam signal processing systems that use the echo-integration method (two echo parameters E1 and E2; Chivers et al. 1990). It has been successfully employed in various settings worldwide (e.g., Schlagintweit 1993; Greenstreet et al. 1997, 2010; Cholwek et al. 2000; Foster-Smith et al. 2000; Wilding et al. 2003; Penrose et al. 2005; ICES 2007; Mielck et al. 2014; Wölfl et al. 2014; see also Hamilton 2005).

There are various approaches to work with RoxAnn data (e.g., ICES 2007; Greenstreet et al. 2010; Serpetti et al. 2011; Mielck et al. 2012; Wölfl et al. 2014), and almost all of them use the data for classification of the seafloor. In this respect, Greenstreet et al. $(1997,2010)$ introduced a method to produce false color composite images (FCCIs) to assimilate RoxAnn's E1, E2 and bathymetric data by directly addressing RGB (red green blue) color channels. However, attempts to produce interpolated maps based directly on both echo parameters E1 and E2 and without further classification are sparse.

This study introduces an improved version of this method, evaluates its ability for seafloor investigations with and without classification, and applies it to new RoxAnn data from a monitoring site west of the island of Helgoland in the SE North Sea. The hydroacoustic and ground-truth data were collected during four surveys spanning the time period 20112014. The ultimate aim is to contribute to recommending monitoring strategies within the framework of WIMO ("Scientific Monitoring Concepts for the German Bight"), a German scientific project carried out by an interdisciplinary research consortium addressing various European and German regulations to assess the state of the marine environment in the German Bight (for overviews, see Winter et al. 2014; Winter et al., Introduction article for this special issue).

\section{Materials and methods}

\section{Study area, surveys, samples}

The study area (17 km long, $6 \mathrm{~km}$ wide, $98 \mathrm{~km}^{2}$ ) is located about $2 \mathrm{~km}$ west of the island of Helgoland in the German Bight (SE North Sea). It is about $45 \mathrm{~km}$ from the nearest mainland (Fig. 1) and includes part of the protected area 'Helgoländer Festlandsockel' in the east with Paleozoic and Mesozoic bedrock outcrops (Spaeth 1990). The lower eastern half of the study area comprises the western branch of the halotectonic depression known as the Helgoland Hole (Schmidt-Thomé 1982). Water depths range between 17 and $54 \mathrm{~m}$. The hydrography forms part of the anticlockwise circulation of the North Sea, influenced by semidiurnal tides that are strongly flood dominated in the northern part of the study area (Callies et al. 2011; Stanev et al. 2015). Surface sediments outside the bedrock outcrops include sandy muds

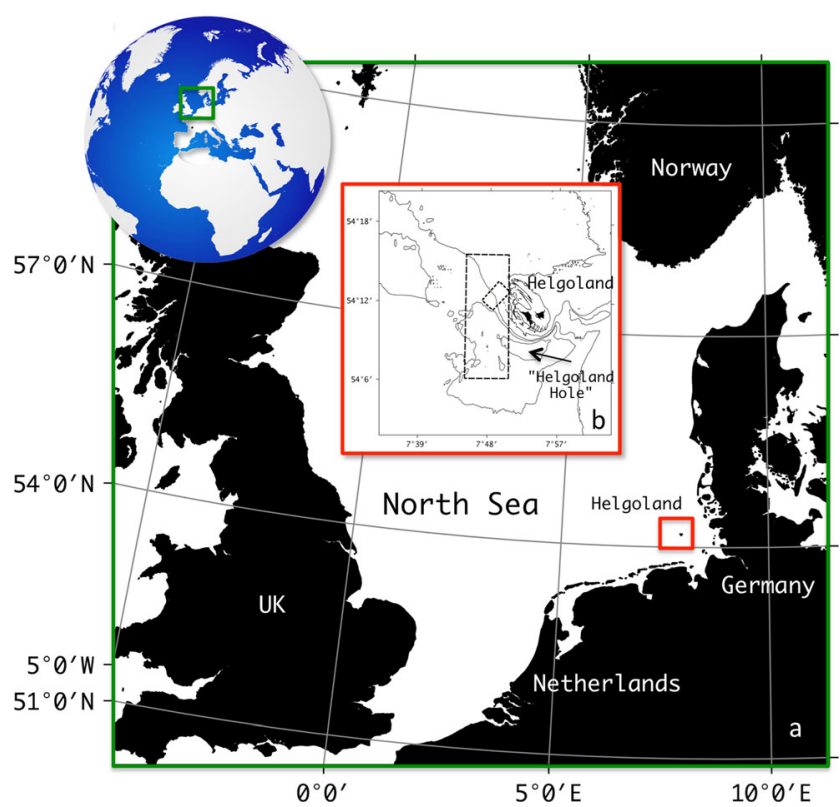

Fig. 1 a Map of the German Bight (North Sea) and study area off the island of Helgoland (red). b Zoom of study area

and muddy sands (Figge 1981). The site was selected because it includes many different habitats, some of them difficult to measure with hydroacoustic gear (cf. steep slopes, large boulders).

The study area was investigated during four RoxAnn surveys between September 2011 and November 2014. During the first two surveys (HE364 in September 2011, and HE411 in October 2013), a small area (3.6 km long, $2.2 \mathrm{~km}$ wide, 7.9 $\mathrm{km}^{2}$, nine transects at $250 \mathrm{~m}$ spacing) in the northeastern sector was investigated twice. The area was selected as being representative for most seafloor types in the region. For the last two surveys, this small area was significantly extended (29 transects at $200 \mathrm{~m}$ spacing) and mapped two times (HE416 in February 2014, and HE435_436 in November 2014). Weather conditions were fair during HE411 and HE416, but poor during HE364 and part of HE435 436.

All surveys were conducted from aboard RV Heincke. The transducer was mounted on an aluminum plate in the moon pool, with measurements on a $24 \mathrm{~h}$ basis at a ship speed of 4-5 knots. Hence, tidal effects in the bathymetric data required compensation. The RoxAnn data were processed as described below. They served to select a total of 105 sites (HE346: 10, HE411: 20, HE416: 45, HE435 436: 30) where bottom sediments were collected with a HELCOM grab sampler after deploying a Kongsberg underwater video system (HE364, $411,416)$ and additionally a GOPRO HD cam (HE435) to gain optical information. The sediment was macroscopically described and photographed. In the home laboratory, grainsize distributions were measured using a CILAS 1180L laser particle sizer (range: 0.04-2,500 $\mu \mathrm{m}$ ) after chemical treatment according to standard procedures (Hass et al. 2010). 


\section{RoxAnn}

The study was carried out using an off-the-shelf RoxAnn GD$\mathrm{X}$ (Sonavision Ltd., Aberdeen, UK) system together with a Furunu 520-5MSD 50/200 kHz dual-frequency transducer and RoxMap acquisition software. The $200 \mathrm{kHz}$ option was used exclusively (data acquisition rate: $1 \mathrm{~Hz}$ ). RoxAnn records a specific part of the tail of the first echo return (E1) and integrates the entire second echo (E2). E1 is thought to be mainly controlled by the roughness of the seafloor; E2 is interpreted to be a measure of the hardness of the seafloor. The E1 and E2 values are given in voltage; the maximum value is $4 \mathrm{~V}$. For more technical details, see Penrose et al. (2005). It must be noted that acoustic descriptors such as 'roughness' and 'hardness' usually relate to acoustic properties of the seabed, rather than seabed characteristics in the common sense (Penrose et al. 2005).

This study is based on a new data-processing routine comparable to the FCCI method of Greenstreet et al. (1997, 2010). After filtering the data to remove poor values, E1 vs. E2 are plotted in an XY diagram. Both axes are then subdivided into 100 units and one color is assigned to each of the four corners. Each color blends with each of the three other corner colors, as depicted in Fig. 2: lower left, green; upper left, blue; upper right, purple; lower right, yellow. These colors proved to be best suited to depict trends by blending the colors. Subsequently, each data point is assigned an RGB code according to the underlain color bins shown in the graph. In total, 10,000 different colors are possible.

In most cases, the color-coded track lines alone are hardly sufficient to characterize a survey area. In such cases, interpolation is helpful. Even though the data may be incorrect in the detail, the interpolated and gridded map (Fig. 3) allows to see broad patterns that cannot easily be recognized in the transect view. It must be noted, however, that measured information is constrained to the transect lines, and discrete features in the non-surveyed areas might go undetected (Brown et al. 2011). The gridding process may also destroy information when the grid scale is larger than the distance from one measured point to the next (Hamilton 2001). In this study, interpolation is accomplished by separating the RGB channels and performing a simple interpolation (natural neighbor method) of the three channels separately. In the next step, the color codes are rebuilt again. The interpolations remain within a certain color domain (e.g., green-red) without crossing colors outside the domain. The distances between the start and end colors are preserved at minimum.

RoxAnn also records the water depth. The bathymetric map used for this study (Fig. 4) has been compiled by means of RoxAnn data, corrected for tidal effects based on information from the Helgoland tide gauge. Data processing and interpolation (natural neighbor) were carried out by means of Matlab (The Mathworks, Inc.) routines.
Fig. 2 Plots of E1 vs. E2 values ('RoxAnn squares') for the four surveys
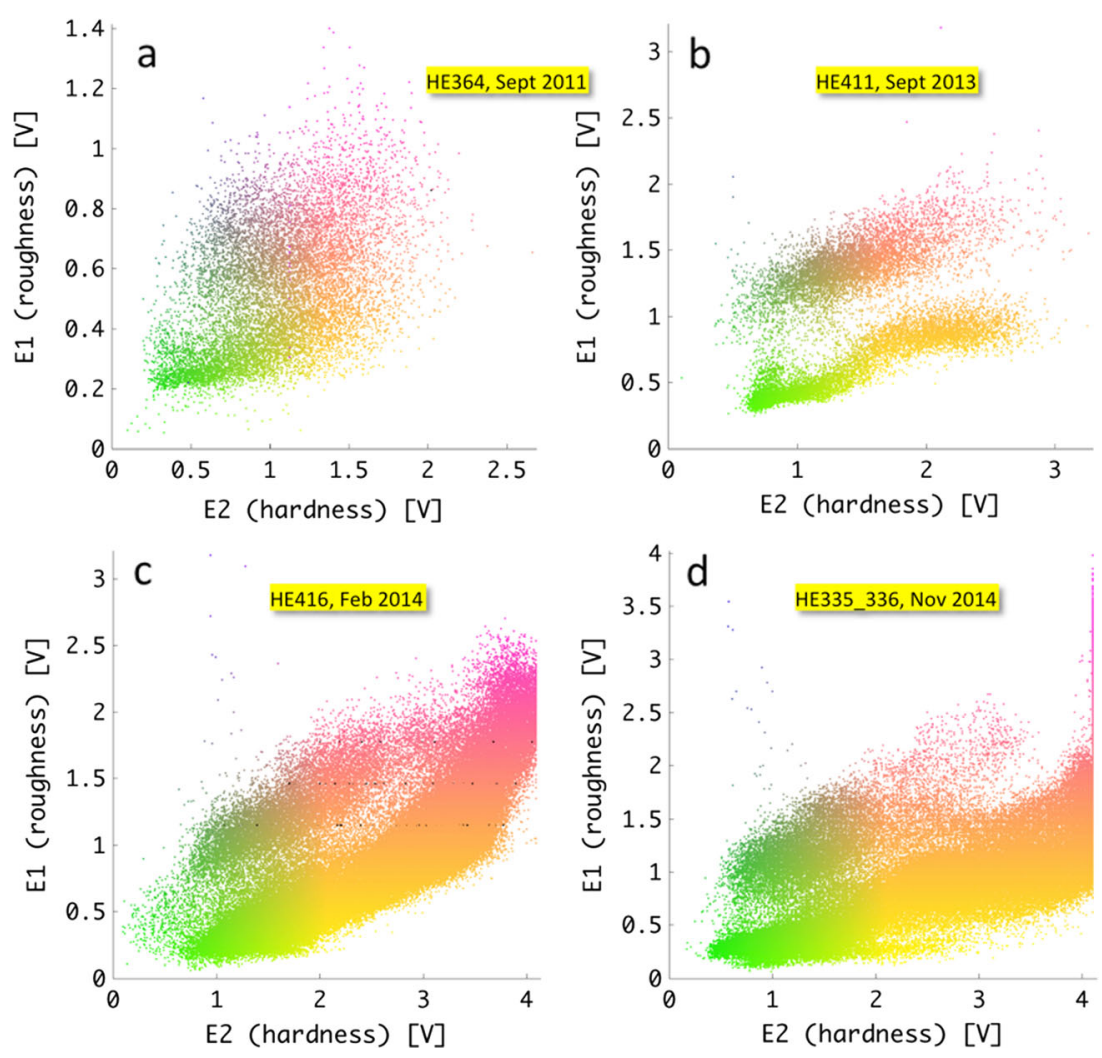
Fig. 3 Interpolated maps of combined E1/E2 values for the four surveys. Underlain is the bathymetry in $10 \mathrm{~m}$ isobaths. Stippled black frame in $\boldsymbol{c}$ and $\boldsymbol{d}$ Area of surveys shown in $\mathbf{a}$ and $\mathbf{b}$. Light blue lines Transect lines of individual surveys
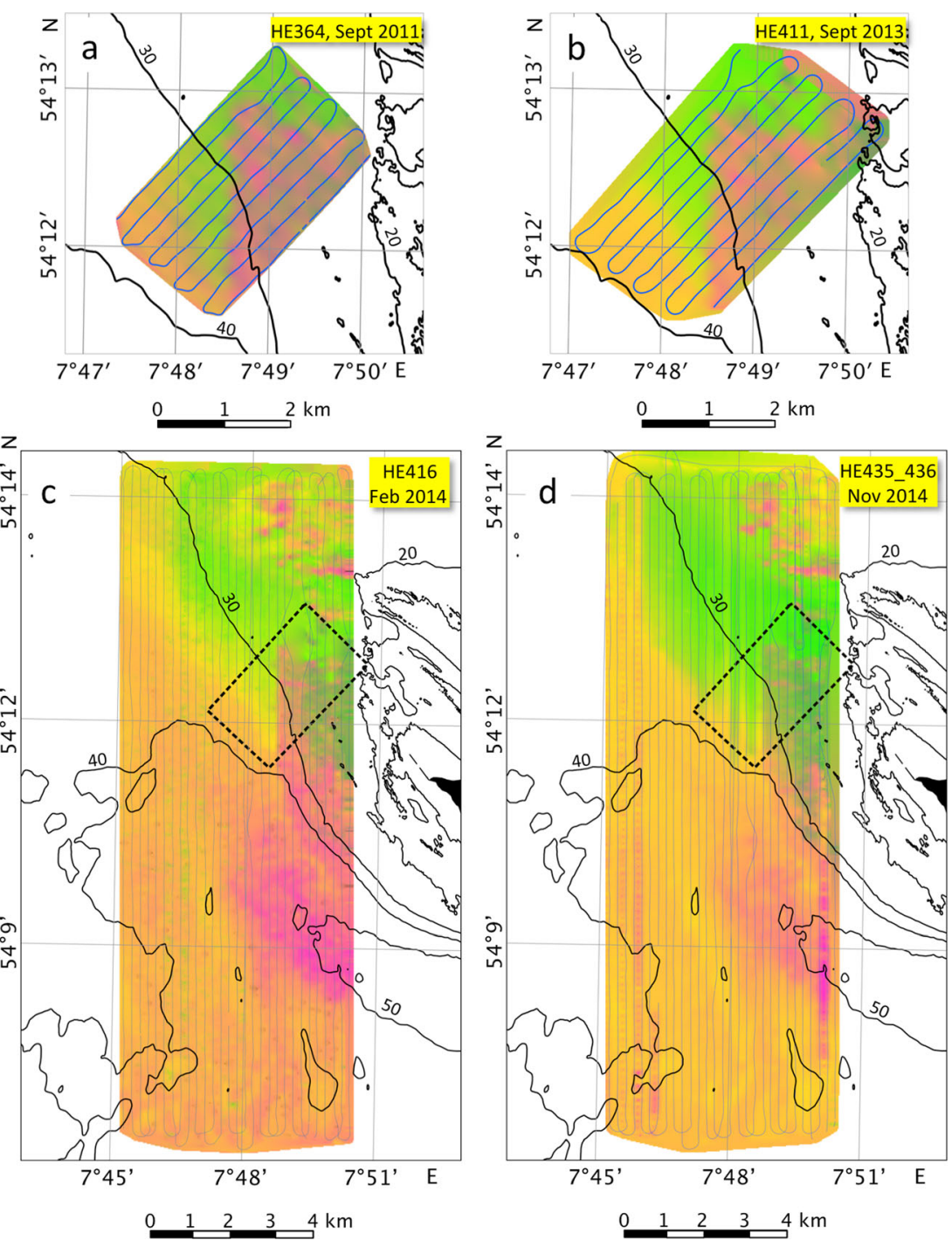

\section{Classification}

The evaluation and comparison of classified and unclassified versions of the RoxAnn data are based on k-means fuzzy clustering analysis (FCA) using the MatLab-programmed tool 'Fuzme' by Budiman (2003). FCA is an unsupervised multivariate classification algorithm that assigns observations to a number of classes (clusters). Observations can be assigned to more than one class ('fuzziness'). The certainty of the class assignment is expressed as 'confusion index' (Burrough et al. 1997). This statistical analysis method was introduced by MacQueen (1967) and has been applied and extended ever since (e.g., Bezdek 1974; Bezdek et al. 1984; Lucieer and Lucieer 2009).

The RGB triplets (see above) form the dataset for the classification. The water depths can be included in the analyses. However, usually these data affect the sedimentdistribution data and produce water depth-controlled seafloor classes. The number of classes must be provided beforehand. It can be assessed on the basis of expert knowledge. However, it is recommended to choose the optimum number of classes on the basis of testing the results of a 2-5-class model for the best proportion of variance explanation. The following parameters can be changed by the user: phi is the exponent (degree) of fuzziness that determines the fuzziness in class membership. Values close to 1 (phi>1) let each item occur only in one cluster ('crisp' classification). Higher values allow membership in more than one cluster ('soft' classification). The default value for phi in this study is 2 . The maximum number of iterations until the cluster position does not change anymore can be set ('maxiter' $=1 \mathrm{e}+6)$. A scatter coefficient can be set that controls the scatter around the initial membership of an item in a cluster ('scatter' $=0.2$ ). Finally, the parameter 'ntry' (set to 100) determines the number of trials to find the optimal solution. 


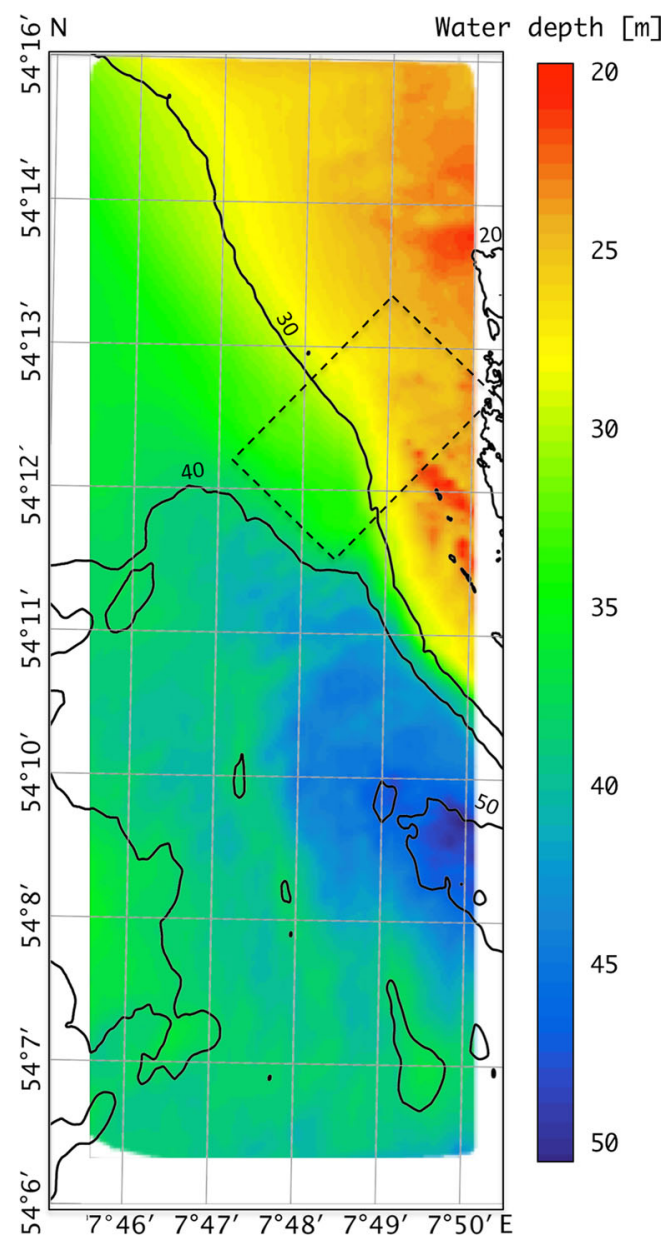

Fig. 4 Bathymetry of study area based on RoxAnn data of survey HE416. Stippled black frame HE364/HE411 survey area

\section{Results}

Figure 4 shows the bathymetry of the study area. It reveals that the area is characterized by geological structures that are only partly overprinted by marine sediments.

\section{RoxAnn}

After data filtering and processing, the following number of pings remained for the analyses: 12,274 (79\%, He364), 13,921 (96\%, HE411), 147,926 (94\%, HE416), 158,463 (97\%, HE435 436). It became evident that different sea states affected the backscatter. As a consequence, the data used for the analyses were neither stretched nor compressed to fill a certain data space equal for all surveys. Instead, RGB coding was adjusted to the maximum E1 and E2 values with slight differences between the surveys. As a result, the color patterns are better comparable between the surveys. The range of E1 and E2 values of the single surveys are depicted in Fig. 2. The lowest range of values and the highest share of poor values filtered out of the data occur in the HE364 data set that was recorded during bad weather conditions (see above). The highest values were recorded during HE435 436. In this data set, the highest E2 values appear to have exceeded the maximum possible value of $4.1 \mathrm{~V}$. Hence, all values $>4.1$ were automatically set to $4.1 \mathrm{~V}$ by the acquisition software.

Figure 2 shows the E1/E2 diagrams after color coding (see above), and Fig. 3 the merged and interpolated E1, E2 values as maps. Since the colors represent the combination of E1 and E2, the E1/E2 diagrams (also known as RoxAnn squares) serve as legends for Fig. 3. The RoxAnn squares reveal two distinct point accumulations (Fig. 2): one in the 'rougher' (upper) part of the box (PA1) and the other one outside PA1 (Fig. 5), generally revealing increasing roughness with increasing hardness values (PA2).

The color-coded data and interpolated maps suggest six acoustic zones (RoxAnn zones, RZs), of which RZ4 occurs exclusively outside the smaller areas of HE364 and 411 (stippled box in Fig. 5). For reasons discussed below, the present study marks fuzzy zones rather than defining hard boundaries between the RZs. RZ1 marks the smoothest and softest sediments of the study area, occurring in the northern sector. RZ2 characterizes harder and slightly rougher sediment that basically forms the transition between RZ1 and RZ3.

In the upper eastern corner of the study area, a slightly darker zone suggests rougher signatures than for the rest of RZ2. The data points plot where PA1 and PA2 would overlap (Fig. 5). RZ3 appears to be clearly harder and rougher than RZ2. It covers most of the western and southern sectors of the study area. RZ4 marks the hardest and roughest signatures of the study area, which occur almost exclusively in the vicinity of the Helgoland Hole and its extension to the west. RZ5 and RZ6 form the 'rougher' point cloud above RZ1-3. RZ5 occurs at the transition between the bedrock outcrops and RZ1 and 2, whereas RZ6 marks the outcrops themselves. This pattern of RZs occurs in all of the surveys.

\section{Ground truthing}

Figures 6 and 7 depict details of the grab samples taken in the study area. The raw data are reported in ESM Table 1 in the electronic supplementary material available online for this article. Grain-size frequency distributions reveal that $>25 \%$ of the samples are bimodal. Hence, it is suggested to utilize the modal value rather than the mean grain size for further interpretation. The mean values of the samples range between 16 (fine-medium silt) and $427 \mu \mathrm{m}$ (medium sand).

Figure 6 shows the distribution of the samples in the study area. Although the grain-size classes tend to be logarithmically distributed, the choice of linear classes enables to better distinguish small changes. Generally, the area is characterized by sandy sediments. There are 18 samples that have a silty mean grain size, but only three samples also have their first mode in the silt class. A zone of finer sediments $(<200 \mu \mathrm{m})$ 
Fig. 5 Locations of PA1, PA2, and the manually classified RoxAnn zones (RZs) a in the RoxAnn square and $\mathbf{b}$ on the interpolated map: example of HE416 (see text for further explanation). Stippled black frame HE364/HE411 survey area
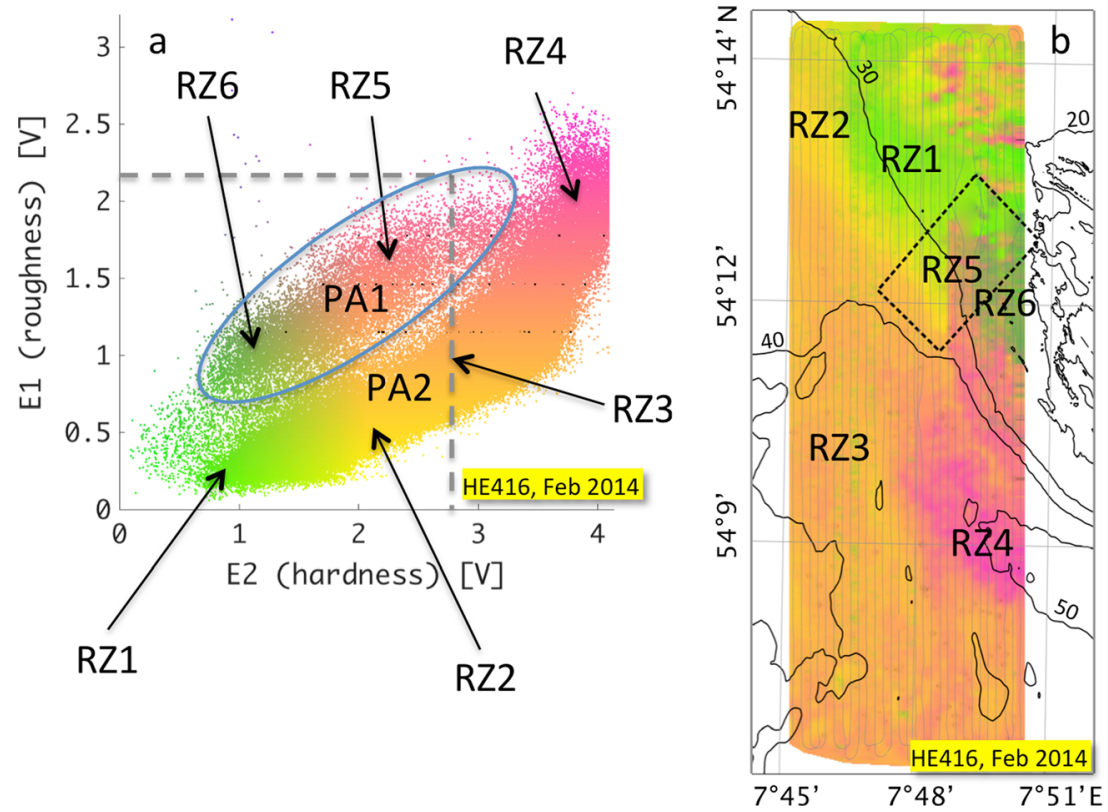

stretches SE-NW through the northern half of the study area. North and south of this zone, sediments are coarser.

No successful sampling of the seafloor was possible in several places in the vicinity of outcropping bedrock close

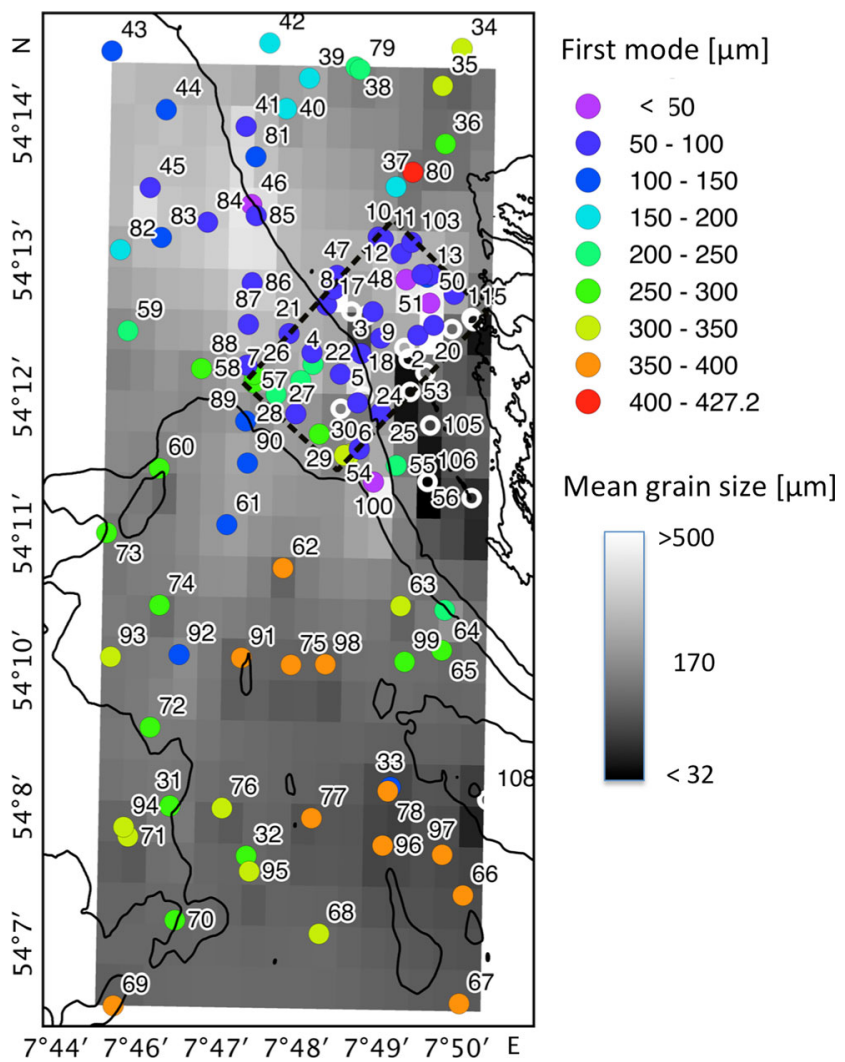

Fig. 6 Positions, codes and first mode (cf. legend) of grab samples for ground truthing. Sample codes refer to ESM Table 1 in the electronic supplementary material. Numbered white rings Unsuccessful sample locations. Gray shading Interpolated mean grain size. Stippled black frame HE364/HE411 survey area to Helgoland (RZ5, 6). Despite numerous attempts, it was only sporadically that the grab sampler collected stones, corals, and rock-inhabiting flora and fauna. Such 'unsuccessful' samples are marked with a white rim in Fig. 6 and 'n/a' in ESM Table 1 in the electronic supplementary material.

According to their frequency distributions, the samples can be subdivided into two classes. Figure 7 depicts the samples in the RZ color of the immediate location from which they were taken. When distributed in classes $>3$ and $<3$ phi (first mode value), the curves occur in a reddish (Fig. 7a) and a greenish class (Fig. 7b), which strongly suggests a relation between the seafloor sediment and/or its typical appearance (bedform) and acoustic reflectivity. Unfitting green colors in Fig. 7a come from random successful grab samples at otherwise stony or gravelly locations or areas characterized by large amounts of shell detritus (e.g., samples 2, 5, 18). Few unfitting reddish colors in Fig. 7b occur because the sediment was essentially very fine-grained (fluid) mud on stones. Here the acoustic signal is 'hard' and 'rough', whereas the sample was muddy (responsible for the modal value). Samples such as nos. 39 and 99 reveal similar conditions, albeit on a smaller scale. They show sand and mud mixtures, but not in the form of sandy mud (see ESM Table 1 in the electronic supplementary material). Sample 39 revealed a thin, $1 \mathrm{~cm}$ thick layer of sand lying on top of a very soft mud deposit. Sample 99 showed sand-filled pockets of $5 \mathrm{~cm}$ and more encapsulated in the otherwise mud-dominated deposit.

The underwater video footage was used to complement the information of the grab samples. During the surveys, the visibility was often significantly impaired due to suspended matter close to the seafloor. As a result, the video data could not be analyzed systematically. 
Fig. 7 Frequency distributions of grab samples with the first mode a $<3$ phi $(125 \mu \mathrm{m})$ and $\mathbf{b}>3$ phi. Colors RoxAnn colors (Figs. 2, 3) at sampling locations
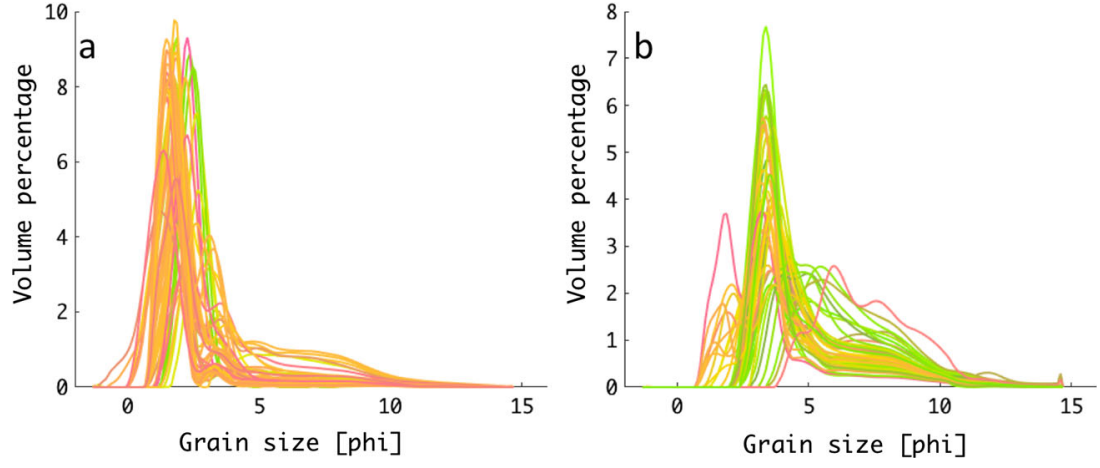

\section{Fuzzy cluster analysis}

By way of example, the results of the FCA are shown for HE411 (Fig. 8) and HE416 (Fig. 9). After running the analysis several times using different numbers of clusters, a 3-class model ('fuzzy cluster' FC) is suggested on the basis of the (interpolated) basic RoxAnn parameters expressed as RGB triplets (see above). In both surveys, FC1 (green) basically comprises the 'hardest' and 'roughest' values that characterize part of the rocky 'Helgoländer Festlandsockel' and the Helgoland Hole. In the smaller working area (HE411), however, this class extends further to the east. FC2 (blue) basically covers the western and southern parts of both working areas. FC3 occurs almost exclusively in the northern and northeastern parts of the larger working area (HE416), whereas it covers the northern and western parts of the small working area.

Figure $9 \mathrm{~b}$ shows the confusion index (CI) for HE416, calculated as part of the fuzzy cluster analysis. The CI is high when there is uncertainty in class membership. This is usually the case at the border between any two classes. There are two zones of high CI values. One includes the eastern part of the small study area. It is exactly where HE411 and HE416 FCA results do not match. The second zone of increased CI is in the upper western corner of the study area where the RoxAnn colors are slightly darker (see above).

\section{Discussion}

The results show a very complex study site with different inclinations and textures that range from fine-grained mud to boulders. RoxAnn data reveal generally two elongated point clouds (PA1 and PA2) in the RoxAnn square but no clear further point accumulations. Figure 5 shows that there are predominantly gradual boundaries between the different types of seafloor, which prevent more distinct point clusters to form. Acoustic backscatter is not only the result of grain size (Goff et al. 2000; Richardson et al. 2001; Ferrini and Flood 2006; Daniell et al. 2015) - bedforms (e.g., ripples) and biogenic structures (e.g., corals) influence the roughness of the seafloor
Fig. 8 Distribution of classes of fuzzy k-means cluster analysis a along the transects and $\mathbf{b}$ interpolated. Example of HE411
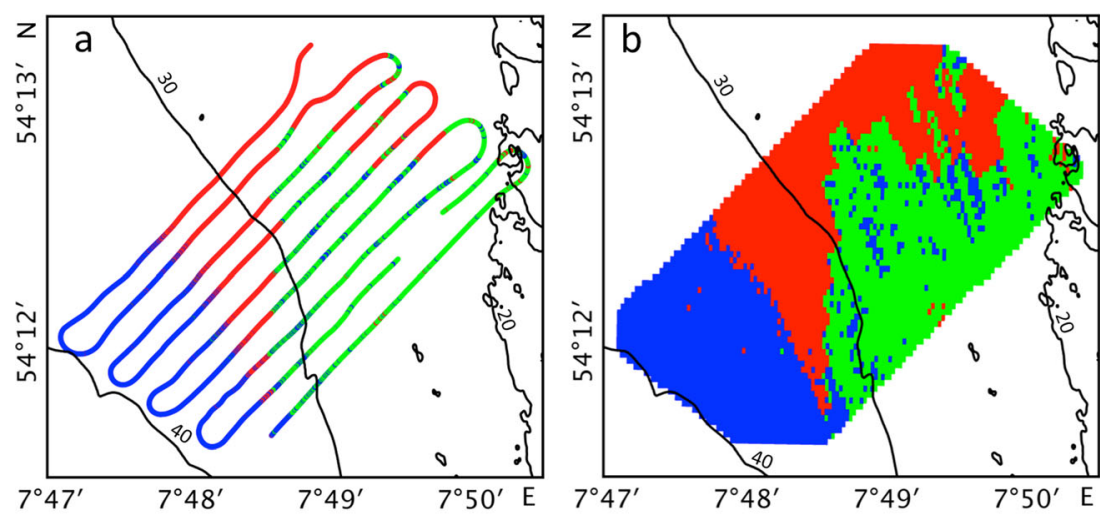

Fuzzy cluster (FC)

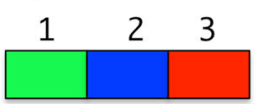


Fig. 9 a Distribution of classes of fuzzy k-means cluster analysis in the study area. b Confusion index. Example of HE416
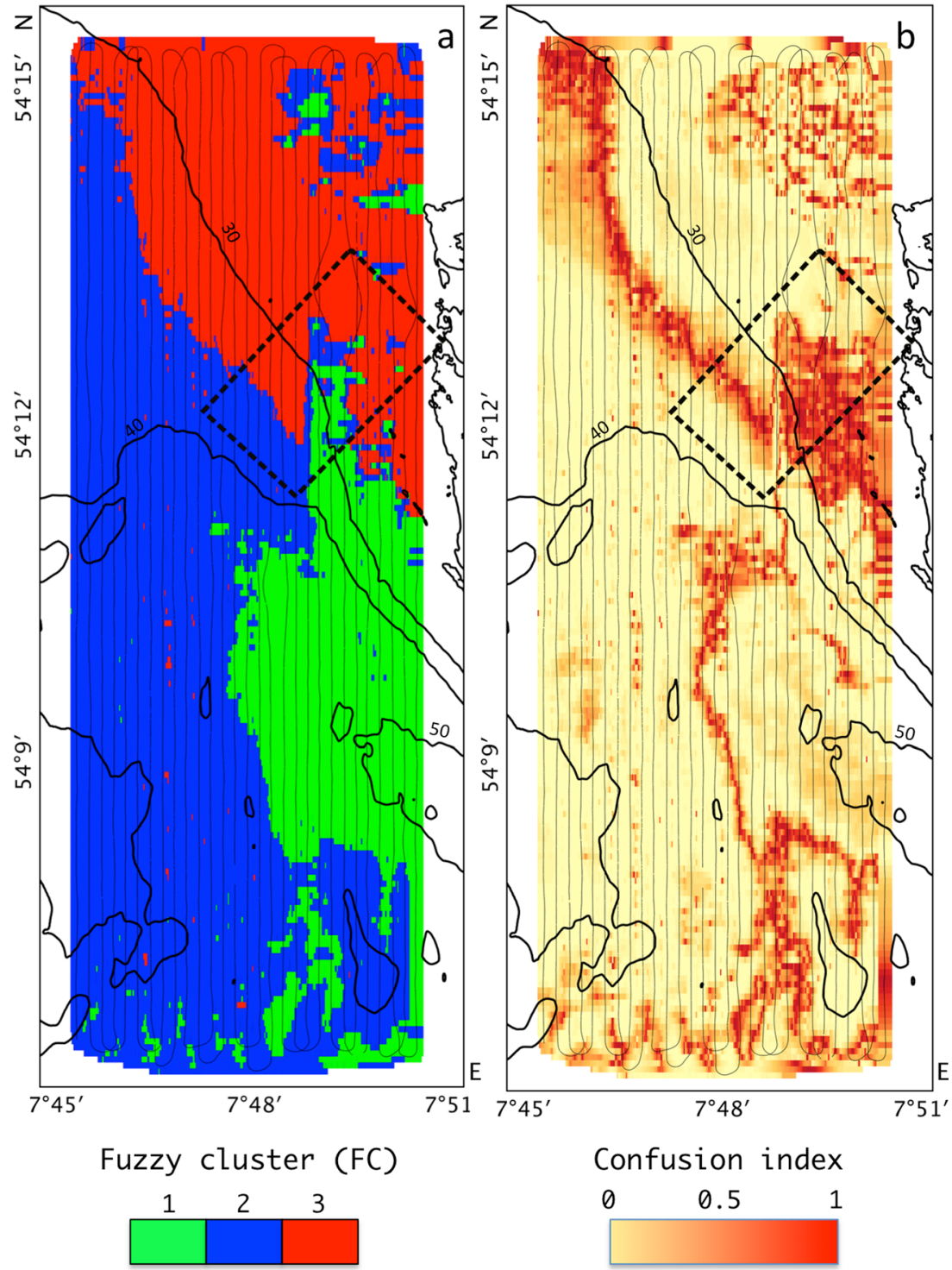

and hence the backscatter as well. Consequently, this study does not define hard boundaries between the RZs.

\section{PA1: Stones and boulders}

The color code in combination with ground-truth data allows further subdivision of PA1 into RZ5 (smaller stones and gravel in a muddy matrix) in the western and RZ6 (large rocks and boulders) in the eastern part of the outcropping 'Helgoländer Festlandsockel' within the small working area. Although the eastern part should be rougher and harder, the RoxAnn data suggest softer and smoother signatures in the eastern than in the western part (Figs. 3 and 5).

Under certain conditions, large rocks and boulders reflect the sound pulses away from the transducer because the inclination of the reflecting panes of the rocks and stones is likely too high. As a result, less backscatter energy is received by the system, which (erroneously) suggests a softer and smoother seafloor in such areas. When the inclination of the seafloor is greater than half the beam width of the transducer, the second echo cannot be received at all anymore (Jagodzinski 1960 in Voulgaris and Collins 1990; Hamilton et al. 1999). This system-inherent effect has also been observed in other studies (Hamilton et al. 1999; Brekhovskikh et al. 2003). Although difficult to handle, this effect appears to be predictable rather than random. The occurrence of RZ6 in only one defined sector of the study area and the discrete occurrence of this class in the E1/E2 diagram confirms this interpretation.

An alternative explanation might be the dense cover of corals (Alcyonium digitatum, 'dead man's fingers') and other living organisms that likely absorb much of the second echo. There is evidence for dense benthic cover from video and grab samples. More investigation during future surveys would cast light on the differences between RZ5 and RZ6. 


\section{PA2: Muddy to sandy environments in the west, shells and stones in the east}

PA2 includes all the remaining RZs (1-4). Here also the color code allows to gain much more information about the seafloor (Figs. 3 and 5). RZ4 occurs in the extension of the Helgoland Hole. There is only scant ground-truth information for the central part of the occurrence of RZ4 in the study area. Nevertheless, it reveals that RZ4 characterizes a seafloor covered abundantly with large shells. Most of them stem from the European oyster (Ostrea edulis) that became extinct in the North Sea during the first half of the 20th century (Franke and Gutow 2004).

RZ3 covers large areas of the southern and western part of the study site. It corresponds to very fine to medium sandy types of seafloor. RZ2 marks coarse silty to fine sandy areas predominantly in the northern half of the study site where it borders RZ3 to the north and RZ1 to the south. RZ1 comprises the fine-grained seafloor types that occur almost exclusively in the northern part of the study area.

Holler et al. (this volume) explain the increasing roughness to the southwest of this area (RZ2 to RZ3) with the increasing occurrence of the ophiurid Amphiura filiformis. The arms of this small suspension feeder protrude millimeters to a few centimeters from immediately below the sediment surface. It might well be that the presence of this highly abundant species ( $>1,500$ ind. $/ \mathrm{m}^{2}$ in the southwestern part of the study area; Holler et al., this volume) accounts for the increased roughness of the seafloor. Ground-truth samples, however, indicate a slight coarsening, which also corresponds to the increased hardness values. Most likely the acoustics are affected by a combination of both grain size and benthos in this area.

\section{Classification with hard and soft boundaries}

Fuzzy clustering is widely used in seafloor classification as it allows to better assess natural conditions that are usually inherently fuzzy (Lucieer and Lucieer 2009; Ostrovsky and Tęgowski 2010; Wölfl et al. 2014). The 'hard' FCA classification carried out for this study largely matches the 'soft' RZ classification. FC1 includes the stony, coarse-grained RZ4; FC2 covers the largely sandy RZ2 and 3, and FC3 marks the fine-grained RZ1. The FCA results suggest sharp borders that facilitate areal calculations important for stakeholders (FosterSmith et al. 2007; Lucieer and Lamarche 2011). The degree of uncertainty can be obtained as a confusion matrix to complement the classification if necessary (Fig. 9). However, there are important details that are revealed neither by the FCA nor by ground truthing, and also not by a combination of both.

These include the separation between RZ5 and RZ6. In this area in the eastern part of the small study site, several grab samples failed due to the rocky seafloor. Those that were successful delivered information only on the sediment juxtaposed between rocks and stones. In HE411, the FCA includes RZ5 in the 'stony' FC1. In HE416, the FCA includes RZ5 in the fine-grained FC3. Both interpretations are wrong, as suggested by Figs. 3b, c and 5 in which RZ5 is clearly distinguished. Cluster models with more than three classes in the FCA of the two areas were also not able to reveal RZ6 as a separate class.

In this context, the largely unclassified RoxAnn data (Fig. 3) not only provide crucial information that cannot be gained otherwise, but also reveal how the interpreted seafloor types (habitats) are distributed. The highly resolved hardness/ roughness parameters add significant information on trends of the seafloor (e.g., fluctuations in seafloor types over short distances). This allows to interpret the stability of the seafloor, as well as the tendency and direction of possible future change, an important aspect for mapping and monitoring activities.

All RZs in Fig. 3 appear to be cloudy, suggesting fluctuations within the RZs. Despite the obvious differences in the overall gain between the surveys for this study (see Results above), the data are well comparable revealing only minor fluctuations within RZ1-4 but clear change within RZ5 and 6 over time. During HE416 and HE435_436, increasing occurrence of fluid mud was observed in the northeastern part of the small study site. In exactly this area, FCA shows one of two high confusion areas (Fig. 9).

The second area of similarly high confusion values occurs at the northwestern edge of the large working area. Samples from this sector $(42,43,44)$ are slightly coarser and better sorted (43 is the third-best sorted sample of the HE416 set) than other samples in their respective RZs. Samples 43 and 44 (both unimodal) show slightly coarser first modes than their respective mean grain sizes. Backscatter is highly susceptible to larger grain sizes (Goff et al. 2000) and to sorting, in particular when the largest grain size approaches the acoustic wave length used (here $\sim 0.75 \mathrm{~mm}$; Ferrini and Flood 2006). This could be one reason for the slightly 'rougher' (cf. more backscatter) values causing confusion in the fuzzy cluster assignment. Another reason could be that better sorting would reflect more vigorous bottom currents that, in turn, would focus ripples on the seafloor and hence cause rougher RoxAnn values.

Both sectors of higher confusion values witness fluctuating sediment import into the northern part of the study area. In particular during the winter survey (HE416), fluid mud, mud patches in a sandy matrix, and thin sand layers on mud patches were observed at the northern study site. Sometimes there were clear traces of mud on the grab sampler although it grabbed only stones or returned empty (RZ6). Mud accumulations in the central North Sea are rare, although strongly increased mud mobilization in the coastal areas during the winter time is a common process (Chang et al. 2006; Papenmeier et al. 2014; Stanev et al. 2015). One of the few 
mud deposits is only $10 \mathrm{~km}$ east of the study site: the 'Helgoland mud area' accumulated more than $30 \mathrm{~m}$ of mud of probably the same source during the Holocene (von Haugwitz et al. 1988; Hebbeln et al. 2003). The observation of sand and mud import into the northern part of the study area where bottom currents are flood-dominated (ENE-directed; Stanev et al. 2015) and the rare occurrence of fine mud deposits at the study site suggest that most of the fine-grained mud is being routed across the area to the east. Coarser grains may become entrapped between rocks and boulders along this route, and add to the lag sediments in RZ4-6.

\section{Mapping without classification?}

Whether or not it is helpful to classify and generalize hydroacoustic data has been discussed from many points of view (e.g., Hamilton 2005; Penrose et al. 2005; McCauley and Siwabessy 2006; ICES 2007; Greenstreet et al. 2010; Henriques et al. 2015). However, most of the discussion is on the approaches, rather than on the classification itself (Snellen et al. 2011). For subsequent classification of RoxAnn data, numerous studies have presented interpolated E1 and E2 maps (e.g., Mielck et al. 2012, 2014; Henriques et al. 2015) and/or transect maps showing the E1 and E2 parameters separately and/or merged together (e.g., Hamilton et al. 1999; Serpetti et al. 2011). Studies reporting an interpolated map of the two RoxAnn parameters in an unclassified combination are rare. Although each of the 10,000 color bins produced by the processing method used here technically represents a category, the large number of these bins and the nonserial numbering (each category carrying its individual RGB signature) largely circumnavigate the construction of artificial categories, which is a problem with many other interpolation methods (ICES 2007; Mamede et al. 2015).

There is clearly a need for a sufficiently small number of standardized seafloor classes that allow area-size determinations and comparisons with similar areas over larger distances (e.g., Shumchenia and King 2010; Calvert et al. 2015; BSH 2016). From a scientific viewpoint, however, such classification is not recommended as it hampers the gain of new scientific knowledge by reducing the information content to an unknown degree. In the example presented here, a 3-class model might be suitable today. In the future, however, there may be changes that would go unnoticed if the data were constrained into the same 3-class model to enable comparison through the years.

Categorical seafloor classes in an environment of gradual transitions would likely not recognize significant changes within these transitional zones (e.g., the transition from RZ1 to RZ3). A small change in RZ6 might cause the automated classification to switch from $\mathrm{FC} 1$ to $\mathrm{FC} 3$ for the RZ6 area, and hence signal large change. In fact, neither FC3 nor FC1 are even suitable classes for RZ6. Constraining the results into predesigned classes to make them comparable to earlier monitoring results would be scientifically unsound.

More sophisticated analysis tools like object based image analysis (Lucieer and Lamarche 2011; Diesing et al. 2014) applied to the example given here would likely solve the problem of classification, but not the fundamental problem of losing information of unknown scientific importance. It is hence suggested to apply expert knowledge to supervise classification routines if categorization of an area is needed. Monitoring activities, in particular hydroacoustic monitoring, do not necessarily need data classification because largely unclassified data much better reveal environmental change. Unclassified data could show unexpected features, processes and trends that may be suppressed when the data are classified.

\section{Conclusions}

The seafloor west of Helgoland was investigated using the acoustic ground discrimination system RoxAnn. The acoustic data were color coded to combine the two backscatter variables (E1, E2) into one variable. After interpolation to achieve area-wide maps based on four monitoring surveys, six seafloor types were identified ranging from rocks and boulders to sandy and muddy habitats. The northern and northwestern parts of the study area reveal sand and mud import, which causes fluctuating conditions in the stony northeastern part while the mostly sandy western and southwestern parts show stable conditions with only minor fluctuations. Fuzzy cluster classification into three classes largely matches these results but has shortcomings in terms of details.

The small area reveals all but one seafloor type of the large study site. Dynamic change occurs predominantly through mud import into the small area. Hence, the small area is suitable for monitoring; the results would be valid also for the large area and probably beyond. Transect distances of 200 $250 \mathrm{~m}$ can be recommended for speedy single-beam monitoring surveys in this area even though smaller line distances would reveal more detail.

RoxAnn is a suitable tool for seafloor investigations but shows reaction to changing sea state and system-inherent problems with rocks and boulders on the seafloor. Groundtruth information is necessary but even many samples cannot provide sufficient information under heterogeneous seafloor conditions. In rocky environments, seafloor sediment samples can even be misleading.

In conclusion, interpretations based on largely non-classified, color-coded and interpolated data provide the best gain of information at the highest possible resolution. Classification with hard boundaries is necessary for stakeholders but may cause reduction of information important to science. There are two main requisites: the need to better understand natural 
systems (for theoretical purposes) and the need to simplify nature (for applied purposes). Thus, it is recommended to always involve expert knowledge in the natural sciences for the application of classification routines. An interpretation based on unclassified data should always be carried out prior to classification to keep the entropy at a high level.

Acknowledgements The authors would like to thank Cpt. Robert Voss and his crew of RV Heincke for their help and cooperation during many surveys. We acknowledge the aid of many students in the frame of internships. This study was carried out within the WIMO project ("Scientific Monitoring Concepts for the German Bight") funded by the Ministry for Environment and Climate Protection and Ministry for Science and Culture of Lower Saxony, Germany. We are grateful to two reviewers and the journal editors for many helpful comments. All data can be downloaded from the PANGAEA data bank (www.pangaea.de).

\section{Compliance with ethical standards}

Conflict of interest The authors declare that there is no conflict of interest with third parties.

\section{References}

Bartholomä A (2006) Acoustic bottom detection and seabed classification in the German Bight, southern North Sea. Geo-Mar Lett 26: $177-184$

Bezdek JC (1974) Numerical taxonomy with fuzzy sets. J Math Biol 1: $57-71$

Bezdek JC, Ehrlich R, Full W (1984) FCM The fuzzy c-means clustering algorithm. Comput Geosci 10:191-203

Brekhovskikh LM, Lysanov IP, Lysanov YP (2003) Fundamentals of ocean acoustics. Springer, Berlin

Brown CJ, Smith SJ, Lawton P, Anderson JT (2011) Benthic habitat mapping: a review of progress towards improved understanding of the spatial ecology of the seafloor using acoustic techniques. Estuar Coast Shelf Sci 92:502-520

BSH (2016) Anleitung zur Kartierung des Meeresbodens mittels hochauflösender Sonare in den deutschen Meeresgebieten. BSH Nr. 7201, 148 pp

Budiman (2003) http://www.mathworks.com/matlabcentral/ fileexchange/4353-fuzzy-k-means/content/contents.m

Burrough PA, van Gaans PFM, Hootsmans RJ (1997) Continuous classification in soil survey: spatial correlation, confusion and boundaries. Geoderma 77:115-135

Callies U, Plüß A, Kappenberg J, Kapitza H (2011) Particle tracking in the vicinity of Helgoland, North Sea: a model comparison. Ocean Dyn 61(12):2121-2139

Calvert J, Strong JA, McGonigle C, Quinn R (2015) An evaluation of supervised and unsupervised classification techniques for marine benthic habitat mapping using multibeam echosounder data. ICES J Mar Sci 72(5):1498-1513

Chang TS, Bartholomä A, Flemming BW (2006) Seasonal dynamics of fine-grained sediments in a back-barrier tidal basin of the German Wadden Sea (Southern North Sea). J Coast Res 22:328-338

Chivers RC, Emerson N, Burns DR (1990) New acoustic processing for underway surveying. Hydrogr J 56:8-17
Cholwek G, Bonde J, Li X, Richards C, Yin K (2000) Processing RoxAnn sonar data to improve its categorization of lake bed surficial substrates dagger. Mar Geophys Res 21:409-421

Cogan CB, Todd BJ, Lawton P, Noji TT (2009) The role of marine habitat mapping in ecosystem-based management. ICES J Mar Sci 66(9): 2033-2042

Daniell J, Siwabessy J, Nichol S, Brooke B (2015) Insights into environmental drivers of acoustic angular response using a self-organising map and hierarchical clustering. Geo-Mar Lett 35:387-403. doi:10.1007/s00367-015-0415-5

Dean BJ, Ellis JT, Irlandi E (2013) Measuring nearshore variability in benthic environments: an acoustic approach. Ocean Coast Manag 86:33-41

Diesing M, Green SL, Stephens D, Lark RM, Stewart HA, Dove D (2014) Mapping seabed sediments: Comparison of manual, geostatistical, object-based image analysis and machine learning approaches. Cont Shelf Res 84:107-119

Ferrini VL, Flood RD (2006) The effects of fine-scale surface roughness and grain size on $300 \mathrm{kHz}$ multibeam backscatter intensity in sandy marine sedimentary environments. Mar Geol 228(1):153-172

Figge K (1981) Karte zur Sedimentverteilung in der Deutschen Bucht im Maßstab 1: 250000. Deutsches Hydrographisches Institut Nr 2900

Foster-Smith RL, Davies J, Sotheran I (2000) Broad scale remote survey and mapping of subtidal habitats and biota. Technical report of the Broadscale Mapping Project. Edinburgh, Scottish Natural Heritage Research, Survey and Monitoring Report no 167

Foster-Smith RL, Brown CJ, Meadows WJ, White WH, Limpenny DS (2004) Mapping seabed biotopes at two spatial scales in the eastern English Channel. Part 2. Comparison of two acoustic ground discrimination systems. J Mar Biol Assoc UK 84:489-500

Foster-Smith B, Connor D, Davies J (2007) MESH Guide to Habitat Mapping. JNCC, Peterborough. http://www.searchmesh.net

Franke HD, Gutow L (2004) Long-term changes in the macrozoobenthos around the rocky island of Helgoland (German Bight, North Sea). Helgol Mar Res 58(4):303-310

Gavrilov AN, Duncan AJ, McCauley RD, Parnum IM, Penrose JD, Siwabessy PJW, Woods AJ, Tseng YT (2005) Characterization of the seafloor in Australia's coastal zone using acoustic techniques. In: Proc Int Conf Underwater Acoustic Measurements: Technologies \& Results, pp 1075-1080

Goff JA, Olson HC, Duncan CS (2000) Correlation of side-scan backscatter intensity with grain-size distribution of shelf sediments, New Jersey margin. Geo-Mar Lett 20(1):43-49

Greenstreet SP, Tuck ID, Grewar GN, Armstrong E, Reid DG, Wrigh PJ (1997) An assessment of the acoustic survey technique, RoxAnn, as a means of mapping seabed habitat. ICES J Mar Sci 54:939-959

Greenstreet SP, Holland GJ, Guirey EJ, Armstrong E, Fraser HM, Gibb IM (2010) Combining hydroacoustic seabed survey and grab sampling techniques to assess "local" sandeel population abundance. ICES J Mar Sci 67(5):971-984

Hamilton LJ (2001) Acoustic seabed classification systems. Defence Science and Technology Organisation, Victoria (Australia), Aeronautical and Maritime Research Lab no DSTO-TN-0401

Hamilton LJ (2005) A bibliography of acoustic seabed classification. CRC Coastal Zone Estuary and Waterway Management, Technical Report 27

Hamilton LJ, Mulhearn PJ, Poeckert R (1999) Comparison of RoxAnn and QTC-View acoustic bottom classification system performance for the Cairns area, Great Barrier Reef, Australia. Cont Shelf Res 19: $1577-1597$

Hass HC, Kuhn G, Monien P, Brumsack HJ, Forwick M (2010) Climate fluctuations during the past two millennia as recorded in sediments from Maxwell Bay, South Shetland Islands, West Antarctica. Geol Soc Lond Spec Publ 344:243-260 
Hebbeln D, Scheurle C, Lamy F (2003) Depositional history of the Helgoland mud area, German Bight, North Sea. Geo-Mar Lett 23(2):81-90

Henriques V, Guerra MT, Mendes B, Gaudêncio MJ, Fonseca P (2015) Benthic habitat mapping in a Portuguese marine protected area using EUNIS: an integrated approach. J Sea Res 100:77-90

Huang Z, Nichol SL, Siwabessy JPW, Daniell J, Brooke BP (2012) Predictive modelling of seabed sediment parameters using multibeam acoustic data: a case study on the Carnarvon Shelf, Western Australia. Int J Geogr Inf Sci 26:283-307

ICES (2007) Acoustic seabed classification of marine physical and biological landscapes. ICES Cooperative Research Report no 286, pp $1-183$

Jagodzinski Z (1960) Multiple echoes in echosounders and the probability of detection of small targets. Int Hydrogr Rev 37:63-68

Kenny AJ, Cato I, Desprez M, Fader G, Schuttenhelm RTE, Side J (2003) An overview of seabed-mapping technologies in the context of marine habitat classification. ICES J Mar Sci 60:411-418

Lucieer V, Lamarche G (2011) Unsupervised fuzzy classification and object-based image analysis of multibeam data to map deep water substrates, Cook Strait, New Zealand. Cont Shelf Res 31(11):12361247

Lucieer V, Lucieer A (2009) Fuzzy clustering for seafloor classification. Mar Geol 264(3/4):230-241

Lurton X, Lamarche G (eds) (2015) Backscatter measurements by seafloor-mapping sonars. Guidelines and recommendations. http://geohab.org/wp-content/uploads/2014/05/BSWG-REPORTMAY2015.pdf

MacQueen J (1967) Some methods for classification and analysis of multivariate observations. In: Cam LM, Neyman J (eds) Proc 5th Berkeley Symp Mathematical Statistics and Probability. University of California Press, Berkeley, pp 281-297

Mamede R, Rodrigues AM, Freitas R, Quintino V (2015) Single-beam acoustic variability associated with seabed habitats. J Sea Res 100: $152-159$

McCauley RD, Siwabessy PJW (2006) Practical guide to acoustic techniques for benthic habitat classification. CRC for Coastal Zone, Estuary and Waterway Management, Indooroopilly, Queensland, Australia, Technical Report 84, pp 1-39

Mielck F, Hass HC, Betzler C (2012) High-resolution hydroacoustic seafloor classification of sandy environments in the German Wadden Sea. J Coast Res 30:1107-1117

Mielck F, Bartsch I, Hass HC, Wölfl AC, Bürk D, Betzler C (2014) Predicting spatial kelp abundance in shallow coastal waters using the acoustic ground discrimination system RoxAnn. Estuar Coast Shelf Sci 143:1-11

Ostrovsky I, Tęgowski J (2010) Hydroacoustic analysis of spatial and temporal variability of bottom sediment characteristics in Lake Kinneret in relation to water level fluctuation. Geo-Mar Lett 30:261-269
Papenmeier S, Schrottke K, Bartholomä A (2014) Over time and space changing characteristics of estuarine suspended particles in the German Weser and Elbe estuaries. J Sea Res 85:104-115

Penrose JD, Siwabessy PJW, Gavrilov A, Parnum I, Hamilton LJ, Bickers A, Brooke B, Ryan DA, Kennedy P (2005) Acoustic techniques for seabed classification. CRC for Coastal Zone Estuary and Waterway Management, Technical Report 32, pp 1-130

Richardson MD, Briggs KB, Williams KL, Lyons AP, Jackson DR (2001) Effects of changing roughness on acoustic scattering: (2) anthropogenic changes. In: Leighton TG, Heald GJ, Griffiths G, Griffiths HD (eds) Proc Inst Acoustics 23(2):343-390

Schlagintweit GEO (1993) Real-time acoustic bottom classification for hydrography a field evaluation of RoxAnn. In: OCEANS'93. Engineering in Harmony with Ocean. Proceedings IEEE:III-214

Schmidt-Thomé P (1982) Geologische Karte von Helgoland mit Erläuterungen. Geologisches Jahrbuch A62. Schweizerbart, Stuttgart

Serpetti N, Heath M, Armstrong E, Witte U (2011) Blending single beam RoxAnn and multi-beam swathe QTC hydro-acoustic discrimination techniques for the Stonehaven area, Scotland, UK. J Sea Res 65:442-455

Shumchenia EJ, King JW (2010) Comparison of methods for integrating biological and physical data for marine habitat mapping and classification. Cont Shelf Res 30(16):1717-1729

Snellen M, Siemes K, Simons DG (2011) Model-based sediment classification using single-beam echosounder signals. J Acoust Soc Am 129:2878-2888

Spaeth C (1990) Zur Geologie der Insel Helgoland. Küste 49:1-32

Stanev EV, Al-Nadhairi R, Valle-Levinson A (2015) The role of density gradients on tidal asymmetries in the German Bight. Ocean Dyn 65(1):77-92

von Haugwitz W, Wong HK, Salge U (1988) The mud area southeast of Helgoland: a reflection seismic study. Mitt Geol-Paläontol Inst Univ Hamburg 65:409-422

Voulgaris G, Collins MB (1990) USP RoxAnn ground discrimination system: a preliminary evaluation. ARE Portland UTH Tech Memo 36/90 RE005314, University of Southampton, Marine Consultancy Services Tech Rep no SUDO/TEC/90/5C, pp 1-75

Wilding TA, Sayer MD, Provost PG (2003) Factors affecting the performance of the acoustic ground discrimination system RoxAnn ${ }^{\mathrm{TM}}$. ICES J Mar Sci 60(6):1373-1380

Winter C, Herrling G, Bartholomä A, Capperucci R, Callies U, Heipke C, Schmidt A, Hillebrand H, Reimers C, Bremer P, Weiler R (2014) Scientific concepts for monitoring the ecological state of German coastal seas (in German). Wasser und Abfall 07-08/2014:21-26. doi:10.1365/s35152-014-0685-7

Wölfl A-C, Lim CH, Hass HC, Lindhorst S, Tosonotto G, Lettmann KA, Kuhn G, Wolff J-O, Abele D (2014) Distribution and characteristics of marine habitats in a subpolar bay based on hydroacoustics and bed shear stress estimates-Potter Cove, King George Island, Antarctica. Geo-Mar Lett 34:435-446 